\title{
Hepatitis E virus mutations associated with ribavirin treatment failure result in altered viral fitness and ribavirin sensitivity
}

Authors: Yannick Debing ${ }^{1 *}$, Christophe Ramière ${ }^{2,3,4,5 *}$, Kai Dallmeier ${ }^{1}$, Géraldine Piorkowski $^{6}$, MaryAnne Trabaud 2 , Fanny Lebossé ${ }^{4,5,7,8}$, Caroline Scholtès ${ }^{2,3,4,5}$, Magali Roche ${ }^{9}$, Catherine LegrasLachuer $^{9,10}$, Xavier de Lamballerie ${ }^{6,11}$, Patrice André ${ }^{2,3,4,5 \S}$, Johan Neyts ${ }^{1 \S}$

* Equally contributing first authors; ${ }^{\S}$ equally contributing senior authors

Affiliations: ${ }^{1}$ Rega Institute for Medical Research, Department of Microbiology and Immunology, University of Leuven, Leuven, Belgium; ${ }^{2}$ Laboratoire de Virologie, Hôpital de la Croix-Rousse, Hospices Civils de Lyon, Lyon, France; ${ }^{3}$ Centre International de Recherche en Infectiologie (CIRI) (Inserm U1111, CNRS UMR 5308), Lyon, France; ${ }^{4}$ Université Claude Bernard Lyon 1, F-69100, Villeurbanne, France; ${ }^{5}$ Université de Lyon, F-69000, Lyon, France; ${ }^{6}$ Aix Marseille Université, IRD French Institute of Research for Development, EHESP French School of Public Health, EPV UMR_D 190 "Emergence des Pathologies Virales", 13385, Marseille, France; ${ }^{7}$ Service d'HépatoGastroentérologie, Hôpital de la Croix-Rousse, Hospices Civils de Lyon, Lyon, France; ${ }^{8}$ INSERM U1052, CRCL (Centre de Recherche en Cancérologie de Lyon), Lyon, France; ${ }^{9}$ ViroScan3D, Trevoux, France; ${ }^{10}$ UMR CNRS 5557 UCBL USC INRA 1193 ENVL, Dynamique Microbienne et Transmission Virale, Lyon , France; ${ }^{11}$ Institut Hospitalo-Universitaire Méditerranée Infection, Marseille, France.

Corresponding author: Johan Neyts - Rega Institute for Medical Research - Department of Microbiology and Immunology - Minderbroedersstraat 10 - 3000 Leuven - Belgium - Tel. +32-1633.73.41 - Fax.+32-16-33.73.40 - Email: johan.neyts@rega.kuleuven.be

Electronic word count: $\underline{6092}$

Number of figures and tables: $\underline{7}$ 
List of abbreviations in order of appearance: HEV, hepatitis E virus; RBV, ribavirin; ALT, alanine aminotransferase; IU, international units; $\gamma \mathrm{GT}, \quad \gamma$-glutamyltransferase; CLL, chronic lymphoid leukemia; NGS, next-generation sequencing; RdRp, RNA-dependent RNA polymerase; HVR, hypervariable region; ORF, open reading frame; IMPDH, inosine 5'-monophosphate dehydrogenase; MPA, mycophenolic acid; LOD, limit of detection; RLU, relative light units; FBS, fetal bovine serum; HS, human serum; WT, wild-type; VC, virus control.

Keywords: hepatitis E virus; chronic hepatitis E; ribavirin; resistance; G1634R; fidelity; RNAdependent RNA polymerase; hypervariable region.

\section{Conflict of interest: None}

Financial support: Yannick Debing received a PhD fellowship from the Research Foundation Flanders (FWO). This project is supported by ANRS (Agence Nationale de Recherche sur le Sida et les Hépatites, 1AO2015), the BELVIR consortium (IAP, phase VII) of the Belgian Science Policy Office (BELSPO) and IWT SBO project HILIM-3D.

Author contributions: Study concept and design: YD, CR, KD, PA, JN; Acquisition of data: YD, CR, GP, MAT, FL, CS, MR, CLL; Data analysis: YD, CR, XdL, PA, JN; Drafting of manuscript: YD, CR; Revision of manuscript: PA, JN. 


\begin{abstract}
Background \& aims: Ribavirin monotherapy is the preferred treatment for chronic hepatitis E, although occasional treatment failure occurs. We present a patient with chronic hepatitis $E$ experiencing ribavirin treatment failure with a completely resistant phenotype. We aimed to identify viral mutations associated with treatment failure and explore the underlying mechanisms.

Methods: Viral genomes were deep-sequenced at different time points and the role of identified mutations was assessed in vitro using mutant replicons, antiviral assays, cell culture of patientderived virus and deep-sequencing.
\end{abstract}

Results: Ribavirin resistance was associated with $\mathrm{Y} 1320 \mathrm{H}, \mathrm{K} 1383 \mathrm{~N}$ and G1634R mutations in the viral polymerase, but also an insertion in the hypervariable region comprising a duplication and a polymerase-derived fragment. Analysis of these genome alterations in vitro revealed replicationincreasing roles for $\mathrm{Y} 1320 \mathrm{H}$ and $\mathrm{G} 1634 \mathrm{R}$ mutations and the hypervariable region insertion. In contrast, the K1383N mutation in the polymerase F1-motif suppressed viral replication and increased the in vitro sensitivity to ribavirin, contrary to the clinical phenotype. Analysis of the replication of mutant full-length virus and in vitro culturing of patient-derived virus confirmed that sensitivity to ribavirin was retained. Finally, deep-sequencing of hepatitis E virus genomes revealed that ribavirin is mutagenic to viral replication in vitro and in vivo.

Conclusions: Mutations $\mathrm{Y} 1320 \mathrm{H}, \mathrm{G} 1634 \mathrm{R}$ and the hypervariable region insertion compensated for $\mathrm{K} 1383 \mathrm{~N}$-associated replication defects. The specific role of the K1383N mutation remains enigmatic, but it appears to be of importance for the ribavirin resistant phenotype in this patient.

\title{
Abstract word count: 236
}

Lay summary: Ribavirin is the most common treatment for chronic hepatitis $E$ and is mostly effective, although some cases of ribavirin treatment failure have been described. Here, we report on a particular case of ribavirin resistance and investigate the underlying causes of treatment failure. Mutations in the viral polymerase, an essential enzyme for viral replication, appear to be responsible. 


\section{Introduction}

Chronic hepatitis $E$ is a persistent infection of the liver by the hepatitis E virus (HEV).[1,2] Although HEV infections are often asymptomatic and resolve spontaneously in healthy people, infections may evolve to chronicity in immunocompromised patients such as solid-organ transplant recipients, HIVinfected individuals and patients with hematological malignancies undergoing chemotherapy.[3] Chronic hepatitis E is now recognized as a major complication in the transplant setting, where an increasing number of cases are reported.[4]

Treatment options for chronic hepatitis E are limited. Reducing immunosuppression is the first intervention for transplant recipients and results in viral clearance in $30 \%$ of patients.[5] The other established options are pegylated interferon alpha or ribavirin (RBV).[6,7] Interferon cannot be used in most transplant patients due to the risk for acute rejection, making RBV the drug of choice in most cases. RBV is usually administered as a monotherapy for at least 3 months and its efficacy against acute and chronic hepatitis $\mathrm{E}$ has been confirmed.[7,8] However, RBV treatment results in several side effects, most prominently anemia, which may necessitate dose reductions and even blood transfusions.[7] RBV treatment failure has been reported, often linked to dose reductions.[8,9] We recently analyzed the viral genomes in two such cases and identified the G1634R mutation associated with treatment failure.[9]

Recent advances in HEV cell culturing, such as the isolation of the cultivable Kernow-C1 p6 strain and several HEV replicons, $[10,11]$ have allowed to explore the molecular virology of HEV and assess its in vitro susceptibility to antiviral drugs (e.g. $[12,13])$. These systems also enabled us to study the mechanism of G1634R in RBV treatment failure. This mutation does not alter RBV susceptibility in vitro, but increases viral replication which may explain the apparent clinical resistance to RBV.[9]

Here we describe a particularly robust case of seemingly RBV-resistant chronic hepatitis E. The onset of RBV failure was associated with multiple mutations and insertions in the viral genome. The role of these alterations was explored using the currently available in vitro tools. 


\section{Materials and methods}

See supplementary file.

\section{Results \\ Patient}

A 68-year-old man was admitted to a hepatology unit for acute hepatic cytolysis with alanine aminotransferase (ALT) levels of 1681 international units (IU)/mL and $\gamma$-glutamyltransferase ( $\gamma$ GT) levels of $379 \mathrm{IU} / \mathrm{mL}$ (figure 1A). Medical history was marked by grade C (Binet classification) chronic lymphoid leukemia (CLL) for which he had received several lines of treatment. At the time of admission, he was treated with a Bruton's tyrosine kinase inhibitor in the context of a clinical trial, allowing control of the hematological disease. Specific investigations revealed acute hepatitis $E$, based on detection of HEV RNA (genotype 3f) in plasma. At the time of diagnosis, the viral load was $5.52 \log _{10}$ copies $/ \mathrm{mL}$. HEV serology was negative for $\operatorname{lgM}$ and $\lg$ because of hypogammaglobulinemia secondary to CLL. The patient was negative for other viruses and there was no evidence of associated vascular, metabolic or autoimmune diseases. Introduction of RBV (800 mg per day) was decided to control viral replication. The evolution was initially favorable and HEV RNA undetectability was obtained after 10 weeks. RBV was stopped after 1 month of undetectability. Eight weeks after RBV cessation, the patient presented a second episode of transaminase flare (ALT = $395 \mathrm{IU} / \mathrm{mL}$ ) and relapse was diagnosed with $6.6 \log _{10}$ copies/mL HEV RNA in the serum. RBV was reintroduced but HEV undetectability could not be achieved: viral loads remained $>6 \log _{10}$ copies $/ \mathrm{mL}$ during the first 6 months following RBV re-introduction. RBV dosage was progressively increased to $1200 \mathrm{mg}$ per day with pharmacological assessments showing correct plasma exposure (residual concentrations $>2 \mathrm{mg} / \mathrm{L}$ ). To date, 58 weeks after RBV re-introduction, HEV could not be eradicated despite a modest decrease in viral load (4.83 $\log _{10}$ copies $/ \mathrm{mL}$ ), a weak improvement of liver function $(A L T=189 \mathrm{IU} / \mathrm{mL}$ ) and the CLL-treatment showing efficacy (lymphocyte count $5.43 \mathrm{G} / \mathrm{L}$ versus $>300$ G/L one year before). 


\section{Viral genome sequencing}

To identify mutations associated with RBV failure, the HEV genome was sequenced by shotgun nextgeneration sequencing (NGS) at different time points: before RBV introduction ( $\mathrm{HEV}_{\text {preRBVres}}$, day 0 ), at the time of relapse ( $\mathrm{HEV}_{\text {relapse, }}$ day 197) and during RBV reintroduction ( $\mathrm{HEV}_{\text {postRBVres, }}$ day 241). Comparison of $\mathrm{HEV}_{\text {preRBVres }}$ and $\mathrm{HEV}_{\text {postRBVres }}$ revealed 3 substitutions in the RNA-dependent RNA polymerase (RdRp), resulting in $\mathrm{Y} 1320 \mathrm{H}, \mathrm{K} 1383 \mathrm{~N}$ and G1634R (figure 1A-C). These substitutions were nearly undetectable in $\mathrm{HEV}_{\text {preRBVres }}(<0.5 \%)$, detected at low levels in $\mathrm{HEV}_{\text {relapse }}(1.8 \%, 2.9 \%$ and $6.5 \%$, respectively), but were highly predominant in $\operatorname{HEV}_{\text {postRBVres }}(95.0 \%, 99.5 \%$ and $95.3 \%$, respectively). Sanger sequencing confirmed the continued presence of these mutations at day 600 (data not shown). We previously found G1634R in RBV treatment failure.[9] The $\mathrm{Y} 1320 \mathrm{H}$ mutation is located in the N-terminus of the presumed HEV RdRp,[14] whereas K1383 is part of the F1-motif and is highly conserved among positive-sense RNA viruses (figure 1C, supplementary figure 1).[15]

An additional mutation was found in the hypervariable region (HVR), resulting in A723V. This substitution was present in $99 \%$ of aligned reads in $\mathrm{HEV}_{\text {postRBVres }}$ and could already be detected in $\mathrm{HEV}_{\text {preRBVres }}$ and $\mathrm{HEV}_{\text {relapse }}$ at frequencies of $17 \%$ and $19.2 \%$, respectively. Furthermore, a large inframe $282 \mathrm{bp}$-insertion in the HVR was found in $\mathrm{HEV}_{\text {postRBVres, }}$ consisting of a duplicated fragment of 258bp from the HVR and a $24 \mathrm{bp}$ RdRp-derived fragment (figure 1B, supplementary figure 2). The recombination event had already occurred before the first introduction of RBV but mutants bearing the insert represented only a minority at that time (supplementary figure 3). During the second RBV treatment, only the insert-containing HVR was detected.

Finally, alignment of consensus sequences $\mathrm{HEV}_{\text {preRBVres }}$ and $\mathrm{HEV}_{\text {relapse }}$ revealed the occurrence of another substitution at position 647 in the HVR in $\mathrm{HEV}_{\text {relapse }}$ : A647T (figure 1B). However, this mutation was not withheld during the second RBV treatment (reversion to $A$ in $\mathrm{HEV}_{\text {postRBVres }}$ ). No changes in the sequences of ORF2 and ORF3 were observed. 


\section{Impact of RdRp mutations on in vitro p6/luc replication and RBV sensitivity}

To assess the role of the RdRp mutations, the $\mathrm{Y} 1320 \mathrm{H}, \mathrm{K} 1383 \mathrm{~N}$ and G1634R mutations were introduced into the genotype $3 \mathrm{p} 6 /$ luc replicon. The replication capacity and RBV sensitivity of all combinations were assessed in Huh7 cells. As reported before,[9] 1634R resulted in significantly increased viral replication (1.5-fold, supplementary figure 4A). The same applied for $\mathrm{Y} 1320 \mathrm{H}$ (1.7fold) and when both mutations were combined, an additive effect on the increase in viral replication (2.7-fold) was noted. Conversely, the K1383N mutation reduced luminescence to levels comparable to mock-transfection, abrogating viral replication. Combining $\mathrm{K} 1383 \mathrm{~N}$ with $\mathrm{Y} 1320 \mathrm{H}$ and $\mathrm{G} 1634 \mathrm{R}$ rescued viral replication to some extent (4.7-fold increase versus $\mathrm{K} 1383 \mathrm{~N}$ alone, $\mathrm{p}=0.006$ ), but luminescence still only reached $23 \%$ of wild-type signal. Next, RBV sensitivity was assessed (supplementary figures 4B-C). $\mathrm{Y} 1320 \mathrm{H}$ and G1634R did not alter RBV susceptibility. Surprisingly, K1383N-bearing constructs had a significantly increased RBV sensitivity with \pm 2 -fold lower $\mathrm{EC}_{50^{-}}$ values. Although these results contradict the clinical findings, they indicate that the K1383N mutation may play an important role in the antiviral effect of RBV.

\section{Impact of $R d R p$ mutations on chimeric $\mathrm{p} 6 / \mathrm{RdRp}_{\text {preRBVres }} /$ luc}

The clinical isolates and p6/luc replicon are both genotype 3, but still differ to some extent: 19 amino acid differences (4\%) were observed between RdRp sequences when comparing the Kernow-C1 p6 with the clinical isolate $\mathrm{HEV}_{\text {preRBVres. }}$. To test whether these differences affect the impact of the mutations, the patient-derived $\mathrm{HEV}_{\text {preRBVres }} \mathrm{RdRp}$ sequence was swapped into p6/luc, generating $\mathrm{p} 6 / \mathrm{RdRp}_{\text {preRBVres }} /$ luc. This chimeric replicon had a comparable RBV sensitivity as $\mathrm{p} 6 /$ luc (figure $2 \mathrm{~A}$ ), but replicated significantly better (figure 2B). Next, Y1320H, K1383N and G1634R were introduced into $\mathrm{p} 6 / \mathrm{RdRp}_{\text {preRBVres }} /$ luc. The $\mathrm{Y} 132 \mathrm{OH}$ and $\mathrm{G} 1634 \mathrm{R}$ mutations increased replication 1.7- and 2.0-fold respectively and 2.8-fold when combined (figure $2 \mathrm{C}$ ), in line with $\mathrm{p} 6 /$ luc results (supplementary figure 4A). Similarly, K1383N virtually abrogated viral replication which could be partially restored by combining all three mutations (up to $12 \%$ of wild-type, i.e. a 5.4 -fold increase over K1383N single 
mutant). The antiviral data followed the same pattern as observed for $\mathrm{p} 6 /$ luc with $\mathrm{K} 1383 \mathrm{~N}$ increasing

RBV sensitivity and $1320 \mathrm{H}$ and $1634 \mathrm{R}$ not affecting antiviral susceptibility (figure 2D).

Next, we sought to confirm these results in an alternative cell line. Analysis of the mutants in HepG2/C3A cells yielded similar results as in Huh7 cells, although differences were more pronounced. The $\mathrm{Y} 132 \mathrm{OH}$ and G1634R mutations increased replication 8- and 10-fold respectively and 15-fold when combined (figure 2E). Combining both mutations with $\mathrm{K} 1383 \mathrm{~N}$ rescued viral replication to $61 \%$ of wild-type. The K1383N mutation also increased RBV sensitivity in HepG2/C3A cells, but to a much larger extent, with \pm 50 -fold shifts in $\mathrm{EC}_{50}$-values (figure $2 \mathrm{~F}$ ).

\section{K1383N decreases GTP usage efficiency by the RdRp}

We previously established that the in vitro mechanism of action of RBV against HEV depends on the depletion of intracellular GTP pools through inhibition of inosine 5'-monophosphate dehydrogenase (IMPDH) and the antiviral effect of RBV can be reversed by adding guanosine to the culture medium, thus replenishing GTP pools.[12] In addition, the F1-motif (which encompasses residue K1383 for the HEV RdRp) has been implicated in GTP binding for Japanese encephalitis virus.[16] To test whether the K1383N mutation results in altered GTP use by the HEV polymerase, we assessed the susceptibility of wild-type and triple mutant $\mathrm{p} 6 / \mathrm{RdRp}_{\text {preRBvres }} /$ luc to mycophenolic acid (MPA), a specific IMPDH inhibitor, in Huh7 cells.[17] The mutant replicon showed increased sensitivity to MPA with a significantly reduced $\mathrm{EC}_{50}$-value (0.41 vs $0.26 \mu \mathrm{M}$ for wild-type and mutant respectively, $p=0.02$, figure $2 \mathrm{G}$ ), which indeed suggests less efficient GTP usage by the K1383N-containing RdRp. To corroborate this finding, the guanosine concentration required to salvage viral replication was determined. Replicon-transfected Huh7 cells were treated with a fixed RBV concentration and different concentrations of guanosine; the fold-induction in luminescence signal over control cells treated with RBV without guanosine is depicted in figure $2 \mathrm{H}$. Guanosine was significantly more effective in rescuing the replication of the wild-type compared to the triple mutant replicon; overall, a 2-fold higher concentration of guanosine was required for the mutant replicon to reach the same 
fold induction as the wild-type. Taken together, these data suggest that the K1383N mutation leads

to less efficient binding of GTP and consequently a decreased replication and increased sensitivity to the GTP-depleting activity of RBV.

\section{In vitro culture of full-length $\mathrm{p} 6$ and patient-derived HEV}

Next, we introduced $1320 \mathrm{H}, 1383 \mathrm{~N}$ and $1634 \mathrm{R}$ into the full-length Kernow-C1 p6 clone and compared viral replication in Huh7 cells in the presence or absence of RBV. Viral yields in the culture medium after 20 days are presented in figure 3A. Triple mutant $\mathrm{p} 6$ replicates considerably less well than its wild-type counterpart, but retained RBV sensitivity, confirming the results obtained with the replicon.

To rule out that the lack of RBV resistance is a mere artifact of the Kernow-C1 p6 strain which has been adapted to cell culture to some extent,[10] we attempted to culture HEV directly from several serum and plasma samples from this patient. We attempted infection of HepG2/C3A cells using fetal bovine serum-supplemented medium, but also tried to infect Huh7 cells in the presence of human serum, given its stimulatory effects on hepatitis C virus replication.[18] We were unable to detect robust shedding of progeny virus into the culture medium for both cell lines, confirming other reports that noted great difficulty in culturing wild-type HEV.[19,20] Nevertheless, quantifiable amounts of viral RNA were detected intracellularly in several cultures infected with samples taken after onset of treatment failure (figure 3B). Parallel cultures simultaneously infected with the same serum/plasma sample and treated with RBV at $25 \mu \mathrm{M}$ yielded approximately 10-fold lower viral RNA titers than their untreated counterparts. This indicates that even following treatment failure, the virus is still inherently sensitive to RBV.

\section{The HVR insertion increases viral replication with a crucial role for the RdRp-derived fragment}

RBV non-responsiveness in this patient was associated with a duplication, a point mutation (A723V), and the insertion of a short RdRp-derived fragment in the HVR (figure 1B). To assess the role of this specific HVR, we replaced the HVR in the p6/luc replicon with the patient-derived HVR obtained after 
onset of RBV failure (HVR postRBVres) (figure $4 \mathrm{~A})$. This removed the S17 insert,[10] which drastically decreased replication (figure 4B), as could be expected given the important role of the S17 insert in HEV cell culture.[10] To test whether the HVR $R_{\text {postrBVres }}$ affects fitness or RBV sensitivity of the $R d R p_{\text {postRBVres }}$ (triple mutant), we constructed and studied the phenotype of $p 6 / H V R+R d R p_{\text {postRBVres }} /$ luc. This double chimera combined the replication handicaps of $\mathrm{p} 6 / \mathrm{HVR}_{\text {postRBVres }} / \mathrm{luc}$ and triple mutant $\mathrm{p} 6 / \mathrm{RdRp}_{\text {postRBvres }} /$ luc (figure $4 \mathrm{~B}$ ). Subsequently, the effect on RBV sensitivity was determined: $\mathrm{p} 6 /$ /uc and $\mathrm{p} 6 / \mathrm{HVR}_{\text {postRBVres }} /$ luc displayed a similar susceptibility to RBV with $\mathrm{EC}_{50}$-values of $4.7 \pm 2.7$ and

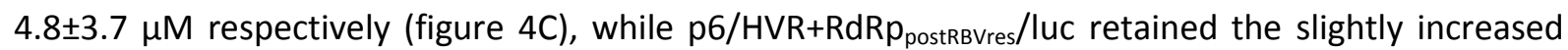
RBV sensitivity of the triple mutant $\mathrm{p} 6 / \mathrm{RdRp}_{\text {postRBVres }} / \mathrm{luc}$ with $\mathrm{EC}_{50}$-values of $2.5 \pm 0.5$ and $1.5 \pm 0.6 \mu \mathrm{M}$ respectively. These data argue against a specific interaction between HVR and RdRp in the context of RBV non-responsiveness and suggest that the HVR is not directly involved in the antiviral activity of RBV, as was anticipated. Next, we assessed the impact of the HVR alterations on viral fitness (figure 4D): $\mathrm{p} 6 / \mathrm{HVR}_{\text {postRBVres }} /$ luc replicated significantly better than $\mathrm{p} 6 / \mathrm{HVR}_{\text {preRBVres }} /$ luc with 1.5 -fold and $2.7-$ fold increases in luminescence signal in Huh7 and HepG2/C3A cells respectively (figure 4E-F), suggesting that the HVR modifications may also be compensatory for the fitness loss associated with the K1383N mutation.

Next, to gain insight in the increased replication in $\mathrm{p} 6 / \mathrm{HVR}_{\text {postrBvres }} / \mathrm{luc}$, we determined the individual contributions of the A723V mutation, the HVR duplication and the RdRp-derived insertion by constructing $\mathrm{p} 6 / \mathrm{HVR}_{\text {preRBVres }} /$ luc with $\mathrm{A} 723 \mathrm{~V}, \mathrm{p} 6 / \mathrm{HVR}_{\text {postRBVres }} /$ luc without RdRp-derived insert and p6/HVR preRBVres/luc with RdRp-derived insert downstream of position 792 (figure 4D). Whereas A723V did not influence viral replication, removal of the RdRp-derived 8aa-insert resulted in a strong reduction in viral replication, i.e. to only $45 \%$ and $31 \%$ of $p 6 / H_{V R} R_{\text {postRBVres }} /$ luc replication in Huh7 and HepG2/C3A cells respectively (figure 4E-F), which highlights the importance of the RdRp-derived insertion in this case. Surprisingly, the addition of the RdRp-derived insert into $\mathrm{p} 6 / \mathrm{HVR}_{\text {preRBVres }} /$ luc completely abrogated viral replication. Taken together, these data suggest that HVR-insertions may 
in general be beneficial for HEV during chronic infection by increasing viral replication, but that

\section{$\mathrm{RBV}$ is mutagenic to HEV replication in vitro and in vivo}

Despite the deleterious effect of K1383N on HEV replication capacity, this virus population still retains the mutation and compensates replication defects with $\mathrm{Y} 1320 \mathrm{H}, \mathrm{G} 1634 \mathrm{R}$ and HVR insertions. This suggests that the K1383N mutation is nonetheless advantageous during prolonged RBV treatment in another way than by increasing viral fitness or antiviral resistance. RBV acts as a RNA virus mutagen in vitro[21,22] and increased mutation rates have been observed in chronic hepatitis $C$ patients treated with RBV, $[23,24]$ whereas in vitro RBV resistance depends on mutations increasing RdRp fidelity. $[25,26]$ The K1383 mutation is located in the F1-motif which is believed to bind the incoming nucleotide-triphosphate in the RdRp and may therefore be important for selecting the correct nucleotide.[15] In fact, the nearby F3-motif has been associated with fidelity[27] and a resistance mutation to $\mathrm{T} 705$, another putative antiviral mutagen,[28] was identified in the RdRp of T705-resistant Chikungunya virus at the exact position (K291R) that corresponds to HEV K1383N.[29] This led us to the hypothesis that RBV may be mutagenic to HEV during extended treatment and that K1383N may alter RdRp fidelity, possibly reducing RBV incorporation into the viral genome.

To test this hypothesis in vitro, deep-sequencing was performed on wild-type and triple mutant HEV p6, cultured with or without RBV for 20 days (figure 3A). No mutations were found with a quasispecies prevalence $>5 \%$ when wild-type HEV was cultured without RBV, whereas 2.47 mutations per kb were found when wild-type HEV was cultured in the presence of $25 \mu \mathrm{M}$ RBV (figure 5A-B, supplementary table 1). Mainly G-to-A and C-to-U mutations were detected, which are the preferred mutations induced by RBV.[21] No known mutations (such as G1634R) were detected and no specific hot-spots for mutations were identified (figure 5B). Surprisingly, when the triple-mutant was cultured in the absence of RBV, 0.80 novel mutations per kb were identified, whereas $\mathrm{Y} 1320 \mathrm{H}, \mathrm{K} 1383 \mathrm{~N}$ and G1634R were not reversed (figure 5C). This increase in the number of mutations compared to wild- 
type could indicate that RdRp fidelity is altered in the triple mutant, but this could also be a consequence of cell-culture adaptation of the mutant construct. Unfortunately, replication of the triple mutant in the presence of RBV was too limited to yield any reliable sequencing results, making it impossible to assess the mutation rate under these conditions.

Finally, deep-sequencing was performed on viral populations in patient sera at different time points to explore a potential mutagenic effect of RBV on in vivo HEV replication. Comparison of the number of mutations present in $>0.5 \%$ of reads at days $4,197,263$ and 686 post-diagnosis indicated a limited number of mutations (63.0 mutations/kb) before the first RBV treatment (day 4 ) and at the time of relapse (day 197, 37.3 mutations/kb) (figure 6A). In contrast, a large number of mutations (212.9 mutations $/ \mathrm{kb}$ ) were detected 66 days after the start of RBV retreatment (day 263). Most of these mutations were either G-to-A or C-to-U mutations (90.5\%, figures $6 \mathrm{~A}-\mathrm{B}$ ), corroborating the mutagenic effect of RBV on HEV replication observed in vitro. Finally, deep sequencing of a late sample (day 686, still under RBV treatment) showed no change in the total number of mutations, while the number of new mutations was strongly reduced (from 186.9 to 63.2 mutations/kb). Moreover, the proportion of G-to-A and C-to-U mutations was reduced as well (56.1\%). This suggests that the mutations may indeed alter RdRp fidelity and reduce the number of RBV incorporation events and consequently the number of mutations. 


\section{Discussion}

RBV treatment of chronic hepatitis $E$ in immunosuppressed patients has shown efficiency in most cases. Nevertheless, treatment failure has been described. $[8,9]$ We report on a robust case of RBV failure in a chronically HEV-infected patient: after a first successful RBV regimen, this patient relapsed and developed complete resistance during retreatment. Sequencing of viral genomes revealed three mutations in the viral RdRp and a HVR-insertion coinciding with onset of treatment failure. A summary of our findings is given in figure 7.

We recently described the G1634R mutation in two patients experiencing RBV treatment failure and proposed that increased viral replication contributes to RBV failure.[9] In these cases, no additional mutations were observed. In the case described here, we believe that G1634R has an adaptive role, compensating for the fitness loss resulting from K1383N.

Amino acid Y1320 is located at the $\mathrm{N}$-terminus of the proposed RdRp sequence,[14] upstream of the F1-motif, but the function of this part of the RdRp is unknown. Contrary to the common occurrence of G1634R in circulating HEV strains,[9] Y1320 is highly conserved in human/swine HEV. Only two sequences with other residues at this position were found: N1320 in the swMN06-C1056 strain isolated from Mongolian pigs[30] (GenBank accession number BAF65208) and H1320 in the CNSH448-08 isolate from a Chinese patient[31] (AGE83345), the latter mutation was also found in the postRBVres sequence in the present case. $\mathrm{Y} 1320 \mathrm{H}$ increased HEV replication without affecting RBV sensitivity and may also be a compensatory mutation for the $\mathrm{K} 1383 \mathrm{~N}$-induced fitness loss.

The K1383N substitution is most intriguing since it strongly decreased viral replication and even increased in vitro RBV sensitivity, contrary to what would be expected based on the clinical phenotype. Position 1383 is located in the RdRp F1-motif and this lysine is highly conserved, also in other families of positive-sense RNA viruses (supplementary figure 1). The selection of K1383N at such a conserved position, despite a strong impact on viral fitness, and the persistence of this mutant during more than a year of retreatment argues for a crucial role in the observed resistance 
phenotype. Based on its localization in the F1-motif, we hypothesized that K1383N may affect RdRp fidelity which could be beneficial in the setting of prolonged RBV treatment. RBV is known to be mutagenic to certain RNA viruses $[21,22]$ and this was also the case for HEV replication in vitro. Unfortunately, the currently available tools did not allow studying the impact of the K1383N mutation on HEV RdRp fidelity: in the presence of RBV, viral replication was too limited to yield reliable deep-sequencing data. Improvements in HEV cell culture systems should allow overcoming this hurdle in the future.

Indeed, despite recent advances, HEV research remains challenging due to the poor in vitro replication, especially for HEV strains derived from patient material, as also observed in this study. The limited viral replication in culture also hampers the study of the effect of mutations or other interventions that decrease HEV replication to some extent, as is the case for the full-length triple mutant when treated with RBV. No robust enzymatic RdRp assay is available and attempts to set up a HEV polymerase assay using isolated crude replication complexes were not successful. Despite these limitations, we clarified the role of several mutations in the context of RBV treatment failure and provided clues on the possible underlying mechanisms. The replication-enhancing properties of $\mathrm{Y} 1320 \mathrm{H}$ and G1634R, especially when combined, as well as the increased replication of the $\mathrm{p} 6 / \mathrm{RdRp}_{\text {preRBVres }} /$ luc chimera may also be useful for other studies requiring robust HEV replication in vitro.

RBV resistance was also associated with an HVR insertion, consisting of HVR- and RdRp-derived fragments. Insertions of host RNA segments or duplicated viral sequences in the HVR have been described and seem relatively common in chronic hepatitis E. $[32,33]$ The exact function of the HVR remains unknown, but insertions may be involved in virus adaptation to the host. Interestingly, similar insertions comprising HVR- and RdRp-derived sequences have been reported before.[33,34] In our patient, selection of this insert was probably not directly related to RBV treatment, but its replication-enhancing properties may have facilitated the emergence of the K1383N mutant, 
together with $\mathrm{Y} 1320 \mathrm{H}$ and G1634R. We tested several combinations of inserts and found that the RdRp-derived insertion was crucial for increasing viral replication, but its mere insertion into $H V R_{\text {preRBVres }}$ abrogated replication. This suggests that particular inserts require a specific context sequence to be beneficial for the virus.

Surprisingly, viremia in the patient remained high whereas we observed a strong decrease in viral replication for the triple mutant constructs. Several hypotheses can be proposed to explain this discrepancy. First, the host genetic background and/or environmental factors could have contributed to the high viral titers in the patient. When comparing the effect of the different mutations in Huh7 and HepG2/C3A cells, large differences in the impact of the mutations on viral replication (figures $2 \mathrm{C}$ and E) were observed. One could hypothesize that specific host factors may have allowed efficient replication of the mutant strain in this particular patient. This also suggests that host factors play an important role in the underlying mechanisms. Comparison of different cell lines may provide an attractive translational model to study differences between patients, e.g. susceptibility to chronic hepatitis $E$, response to RBV and the role of specific mutations. A second potential explanation can be found in the fact that $\mathrm{p} 6 / \mathrm{luc}$, and even the chimeric constructs, have a different background compared to the patient strain. Differences in non-coding regions or non-structural proteins may explain the different replication efficacies observed between both strains. Finally, the in vitro situation is not entirely comparable to the in vivo situation: although the virus replicates efficiently in patients with acute and chronic hepatitis, culturing HEV in cells is very challenging. The factors allowing efficient in vivo replication that are missing in vitro are still unknown, but they may have contributed to the high viral titers observed after onset of ribavirin resistance.

The observed mutagenic effect of RBV, both in vitro and in vivo, has interesting implications for the proposed mechanism of action against HEV. Earlier, we found that RBV's anti-HEV effect was mediated by depletion of intracellular GTP.[12] These phenomena do not need to be mutually exclusive: by depleting intracellular GTP, RBV-triphosphates no longer need to compete with high 
concentrations of GTP and have a higher chance of being incorporated into the viral genome. The relative importance of either mechanism in vivo is unclear.

Relapse following a 3-month course of RBV occurs in a minority of chronically HEV-infected patients. However, subsequent retreatment for a prolonged period leads to viral clearance in most cases, suggesting that the emergence of complex mutants with complete RBV resistance only occurs in a limited number of patients with specific characteristics. An interesting question is whether the kinase inhibitor used for CLL treatment contributed to the clinical phenotype and viral evolution. Therefore, a detailed investigation of the effect of different treatments for hematological malignancies on in vitro HEV replication and on the clinical course of chronic hepatitis $\mathrm{E}$ is warranted.

RBV-resistant hepatitis $E$ is particularly challenging from a clinical point-of-view, given the lack of other effective therapies. Assessing the role of mutations in other cases of RBV failure will be crucial to completely understand the underlying mechanisms and susceptibilities. The experimental use of sofosbuvir, which inhibits in vitro HEV replication, may be an alternative therapeutic option worth exploring in these patients.[35] 


\section{Acknowledgements}

The authors are grateful to Ralf Bartenschlager, Luc Verschaeve, and Suzanne Emerson for supplied materials and to the French "Centre national de reference" for HEV (Jacques Izopet, Toulouse) for viral quantification and genotyping.

\section{References}

[1] Behrendt P, Steinmann E, Manns MP, Wedemeyer H. The impact of hepatitis E in the liver transplant setting. J Hepatol 2014;61:1418-29.

[2] Debing Y, Neyts J. Antiviral strategies for hepatitis E virus. Antiviral Res 2014;102:106-18.

[3] Fujiwara S, Yokokawa Y, Morino K, Hayasaka K, Kawabata M, Shimizu T. Chronic hepatitis E: a review of the literature. J Viral Hepat 2014;21:78-89.

[4] Sayed IM, Vercouter A-S, Abdelwahab SF, Vercauteren K, Meuleman P. Is hepatitis E virus an emerging problem in industrialized countries? Hepatology 2015. doi:10.1002/hep.27990.

[5] Kamar N, Garrouste C, Haagsma EB, Garrigue V, Pischke S, Chauvet C, et al. Factors associated with chronic hepatitis in patients with hepatitis E virus infection who have received solid organ transplants. Gastroenterology 2011;140:1481-9.

[6] Alric L, Bonnet D, Laurent G, Kamar N, Izopet J. Chronic hepatitis E virus infection: successful virologic response to pegylated interferon-alpha therapy. Ann Intern Med 2010;153:135-6.

[7] Kamar N, Izopet J, Tripon S, Bismuth M, Hillaire S, Dumortier J, et al. Ribavirin for chronic hepatitis E virus infection in transplant recipients. N Engl J Med 2014;370:1111-20.

[8] Pischke S, Hardtke S, Bode U, Birkner S, Chatzikyrkou C, Kauffmann W, et al. Ribavirin treatment of acute and chronic hepatitis E: a single-centre experience. Liver Int 2013;33:722-6.

[9] Debing Y, Gisa A, Dallmeier K, Pischke S, Bremer B, Manns M, et al. A mutation in the hepatitis E virus RNA polymerase promotes its replication and associates with ribavirin treatment failure in organ transplant recipients. Gastroenterology 2014;147:1008-11. 
[10] Shukla P, Nguyen HT, Faulk K, Mather K, Torian U, Engle RE, et al. Adaptation of a genotype 3 hepatitis E virus to efficient growth in cell culture depends on an inserted human gene segment acquired by recombination. J Virol 2012;86:5697-707.

[11] Nguyen HT, Shukla P, Torian U, Faulk K, Emerson SU. Hepatitis E virus genotype 1 infection of swine kidney cells in vitro is inhibited at multiple levels. J Virol 2014;88:868-77.

[12] Debing Y, Emerson SU, Wang Y, Pan Q, Balzarini J, Dallmeier K, et al. Ribavirin inhibits in vitro hepatitis E virus replication through depletion of cellular GTP pools and is moderately synergistic with alpha interferon. Antimicrob Agents Chemother 2014;58:267-73.

[13] Wang Y, Zhou X, Debing Y, Chen K, Van Der Laan LW, Neyts J, et al. Calcineurin inhibitors stimulate and mycophenolic acid inhibits replication of hepatitis E virus. Gastroenterology 2014;146:1775-83.

[14] Koonin EV, Gorbalenya AE, Purdy MA, Rozanov MN, Reyes GR, Bradley DW. Computer-assisted assignment of functional domains in the nonstructural polyprotein of hepatitis $E$ virus: delineation of an additional group of positive-strand RNA plant and animal viruses. Proc Natl Acad Sci U S A 1992;89:8259-63.

[15] Bruenn JA. A structural and primary sequence comparison of the viral RNA-dependent RNA polymerases. Nucleic Acids Res 2003;31:1821-9.

[16] Surana P, Satchidanandam V, Nair DT. RNA-dependent RNA polymerase of Japanese encephalitis virus binds the initiator nucleotide GTP to form a mechanistically important preinitiation state. Nucleic Acids Res 2014;42:2758-73.

[17] Sintchak MD, Fleming MA, Futer O, Raybuck SA, Chambers SP, Caron PR, et al. Structure and mechanism of inosine monophosphate dehydrogenase in complex with the immunosuppressant mycophenolic acid. Cell 1996;85:921-30.

[18] Steenbergen RHG, Joyce MA, Thomas BS, Jones D, Law J, Russell R, et al. Human serum leads to differentiation of human hepatoma cells, restoration of very-low-density lipoprotein secretion, 
and a 1000-fold increase in HCV Japanese fulminant hepatitis type 1 titers. Hepatology 2013;58:1907-17.

[19] Nguyen HT, Torian U, Faulk K, Mather K, Engle RE, Thompson E, et al. A naturally occurring human/hepatitis $\mathrm{E}$ recombinant virus predominates in serum but not in faeces of a chronic hepatitis E patient and has a growth advantage in cell culture. J Gen Virol 2012;93:526-30.

[20] Berto A, Van der Poel WHM, Hakze-van der Honing R, Martelli F, La Ragione RM, Inglese N, et al. Replication of hepatitis E virus in three-dimensional cell culture. J Virol Methods 2013;187:327-32.

[21] Crotty S, Maag D, Arnold JJ, Zhong W, Lau JY, Hong Z, et al. The broad-spectrum antiviral ribonucleoside ribavirin is an RNA virus mutagen. Nat Med 2000;6:1375-9.

[22] Ortega-Prieto AM, Sheldon J, Grande-Pérez A, Tejero H, Gregori J, Quer J, et al. Extinction of hepatitis C virus by ribavirin in hepatoma cells involves lethal mutagenesis. PloS One 2013;8:e71039.

[23] Hofmann WP, Polta A, Herrmann E, Mihm U, Kronenberger B, Sonntag T, et al. Mutagenic effect of ribavirin on hepatitis $\mathrm{C}$ nonstructural $5 \mathrm{~B}$ quasispecies in vitro and during antiviral therapy. Gastroenterology 2007;132:921-30.

[24] Asahina $Y$, Izumi N, Enomoto N, Uchihara M, Kurosaki M, Onuki $Y$, et al. Mutagenic effects of ribavirin and response to interferon/ribavirin combination therapy in chronic hepatitis C. J Hepatol 2005;43:623-9.

[25] Pfeiffer JK, Kirkegaard K. A single mutation in poliovirus RNA-dependent RNA polymerase confers resistance to mutagenic nucleotide analogs via increased fidelity. Proc Natl Acad Sci U S A 2003;100:7289-94.

[26] Zeng J, Wang H, Xie X, Yang D, Zhou G, Yu L. An increased replication fidelity mutant of footand-mouth disease virus retains fitness in vitro and virulence in vivo. Antiviral Res 2013;100:17. 
[27] Curti E, Jaeger J. Residues Arg283, Arg285, and Ile287 in the nucleotide binding pocket of bovine viral diarrhea virus NS5B RNA polymerase affect catalysis and fidelity. J Virol 2013;87:199-207.

[28] Baranovich T, Wong S-S, Armstrong J, Marjuki H, Webby RJ, Webster RG, et al. T-705 (favipiravir) induces lethal mutagenesis in influenza A H1N1 viruses in vitro. J Virol 2013;87:3741-51.

[29] Delang L, Segura Guerrero N, Tas A, Quérat G, Pastorino B, Froeyen M, et al. Mutations in the chikungunya virus non-structural proteins cause resistance to favipiravir (T-705), a broadspectrum antiviral. J Antimicrob Chemother 2014;69:2770-84.

[30] Lorenzo FR, Tsatsralt-Od B, Ganbat S, Takahashi M, Okamoto H. Analysis of the full-length genome of hepatitis E virus isolates obtained from farm pigs in Mongolia. J Med Virol 2007;79:1128-37.

[31] Lu Y-H, Qian H-Z, Hu A-Q, Ren H, Qin X, Jiang Q-W, et al. Duration of viraemia in Chinese acute sporadic hepatitis E. Eur J Clin Microbiol Infect Dis 2014;33:755-9.

[32] Shukla P, Nguyen HT, Torian U, Engle RE, Faulk K, Dalton HR, et al. Cross-species infections of cultured cells by hepatitis E virus and discovery of an infectious virus-host recombinant. Proc Natl Acad Sci U S A 2011;108:2438-43.

[33] Lhomme S, Abravanel F, Dubois M, Sandres-Saune K, Mansuy J-M, Rostaing L, et al. Characterization of the polyproline region of the hepatitis $E$ virus in immunocompromised patients. J Virol 2014;88:12017-25.

[34] Johne R, Reetz J, Ulrich RG, Machnowska P, Sachsenröder J, Nickel P, et al. An ORF1-rearranged hepatitis E virus derived from a chronically infected patient efficiently replicates in cell culture. J Viral Hepat 2014;21:447-56.

[35] Dao Thi VL, Debing Y, Wu X, Rice CM, Neyts J, Moradpour D, et al. Sofosbuvir inhibits hepatitis E virus replication in vitro and results in an additive effect when combined with ribavirin. Gastroenterology 2015. doi:10.1053/j.gastro.2015.09.011. 
Author names in bold designate co-first authorship.

\section{Figure legends}

Fig. 1. RBV treatment failure associated with $\mathrm{Y} 1320 \mathrm{H}, \mathrm{K} 1383 \mathrm{~N}$ and G1634R mutations and a HVR insertion. (A) Clinical course and NGS for a chronic hepatitis-E-patient experiencing RBV treatment failure. The frequency of mutations in the quasispecies at the indicated positions is represented by pie charts. * The extended HVR with duplication and RdRp-derived insertion was only detected as a minor variant at these time points (supplementary figure 2). (B-C) Alignment of sequences before (day 0) and after onset of RBV treatment failure (day 241) and during relapse (day 197). For the HVR (B), the duplicated region is underlined, point mutations are indicated in bold and with *, while the RdRp-derived insert is marked with a box. For the RdRp (C), point mutations are indicated with *, while the F1-motif and the origin of the RdRp-derived insert in the HVR are marked with boxes. Numbering is according to NCBI reference sequence NP_056779. ALT, alanine transaminase; үGT, gamma-glutamyl transferase; HVR, hypervariable region; IU, international units; LOD, limit of detection for HEV RT-qPCR assay; RBV, ribavirin; RdRp, RNA-dependent RNA polymerase.

Fig. 2. Replication and antiviral sensitivity of chimeric $p 6 / R_{R R p}$ preRBVres/luc and impact of $Y 1320 \mathrm{H}$, K1383N and G1634R. Comparison of RBV sensitivity (A) and replication (B) of p6/luc and $\mathrm{p} 6 / \mathrm{RdRp}_{\text {preRBVres }} /$ luc. Effect of mutations on $\mathrm{p} 6 / \mathrm{RdRp}_{\text {preRBVres }} /$ luc replication in Huh7 $(\mathrm{C})$ and HepG2/C3A (E), RBV sensitivity in Huh7 (D) and HepG2/C3A (F) and MPA sensitivity in Huh7 (G). (H) Fold-induction of $\mathrm{p} 6 / \mathrm{RdRp}_{\text {preRBVres }} /$ luc replication under $\mathrm{RBV}$ treatment $(30 \mu \mathrm{M})$ by different concentrations of guanosine in Huh7 cells. MPA, mycophenolic acid; RBV, ribavirin; RLU, relative light units. Values represent mean \pm standard deviation (SD) for 3 independent experiments. ${ }^{*} p<0.05, * *$ $p<0.01, * * * p<0.001$.

Fig. 3. In vitro culture of full-length p6 and patient-derived HEV. (A) Huh7 cells transfected with fulllength capped p6 RNA (wild-type or $\mathrm{Y} 1320 \mathrm{H}-\mathrm{K} 1383 \mathrm{~N}-\mathrm{G} 1634 \mathrm{R}$ triple mutant) were cultured with or 
without RBV $(25 \mu \mathrm{M})$. RNA copies in culture medium at day 20 post transfection are depicted. Values represent mean $\pm S D$ for 3 independent experiments. (B) HepG2/C3A cells cultured with $10 \%$ FBS and Huh7 cells cultured with $2 \%$ human serum were infected with day 263 serum (one data point for Huh7) or day 318 plasma (both data points for HepG2/C3A and one for Huh7), intracellular viral RNA was quantified after 20 days. Values represent individual data points. FBS, fetal bovine serum; HS, human serum; RBV, ribavirin; WT, wild-type.

Fig. 4. Impact of the HVR and modifications on viral replication and RBV sensitivity. Chimeric p6/luc

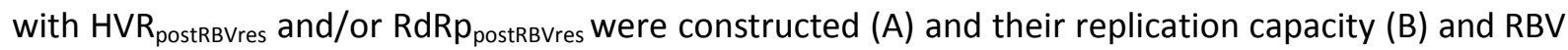
sensitivity (C) were assessed in Huh7 cells. The patient-derived HVR is depicted in green with a grey box for the RdRp-derived insertion; the patient-derived $R d R p$ is depicted in grey with red lines representing the $\mathrm{Y} 132 \mathrm{H}, \mathrm{K} 1383 \mathrm{~N}$ and $\mathrm{G} 1634 \mathrm{R}$ mutations. Comparison of the replication of $\mathrm{p} 6 / \mathrm{HVR}_{\text {preRBVres }} / \mathrm{luc}$ with and without $\mathrm{A} 732 \mathrm{~V}$ (red line), $\mathrm{p} 6 / \mathrm{HVR}_{\text {postRBVres }} / \mathrm{luc}, \mathrm{p} 6 / \mathrm{HVR}_{\text {postRBVres }} /$ luc without

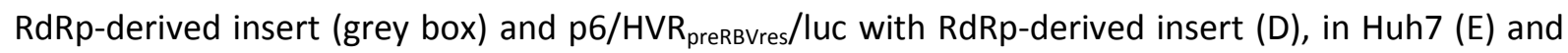
HepG2/C3A (F) cells. RBV, ribavirin; RLU, relative light units. Values represent mean \pm SD for 3 independent experiments. $p<0.05,{ }^{* *} p<0.01,{ }^{* * *} p<0.001$.

Fig. 5. RBV is mutagenic in vitro to wild-type HEV replication, whereas triple-mutant HEV accumulates mutations even in the absence of RBV. (A) The number of mutations per kb present above $5 \%$ in the quasispecies of HEV p6 wild-type or triple RdRp-mutant cultured with or without RBV $(25 \mu \mathrm{M})$ was determined by deep-sequencing. Values are combined from 3 independent experiments. (B-C) Position and frequency of mutations present above $5 \%$ of the quasispecies for wild-type in the absence or presence of RBV (B) or triple mutant (C) for each individual experiment. Areas in grey were successfully deep-sequenced. Red bars represent the mutations introduced into the triple mutant RdRp, which were conserved over the course of all experiments. Mut, $\mathrm{Y} 132 \mathrm{OH}-$ K1383N-G1634R triple mutant; RBV, ribavirin; VC, virus control; WT, wild-type. 
Fig. 6. RBV is mutagenic to in vivo HEV replication. (A) The number of mutations per kb present above $0.5 \%$ in the quasispecies of patient serum-derived HEV was determined by deep-sequencing at different times post diagnosis. (B) The number of new mutations (i.e. not detected at any of the previous time points) per kb present above $0.5 \%$ in the quasispecies of patient serum-derived HEV was determined in the same way.

Fig. 7. HEV genome organization with mutations and their impact. HEV genome organization is depicted with the location of the mutations and insertion. Their impact on in vitro HEV replication and RBV sensitivity is given together with the resulting hypothesis of the present study. HVR, hypervariable region; MTase, methyltransferase; ORF, open reading frame; Pro, protease; RBV, ribavirin; RdRp, RNA-dependent RNA polymerase; UTR, untranslated region; $X$, macrodomain; $Y, Y$ domain. 


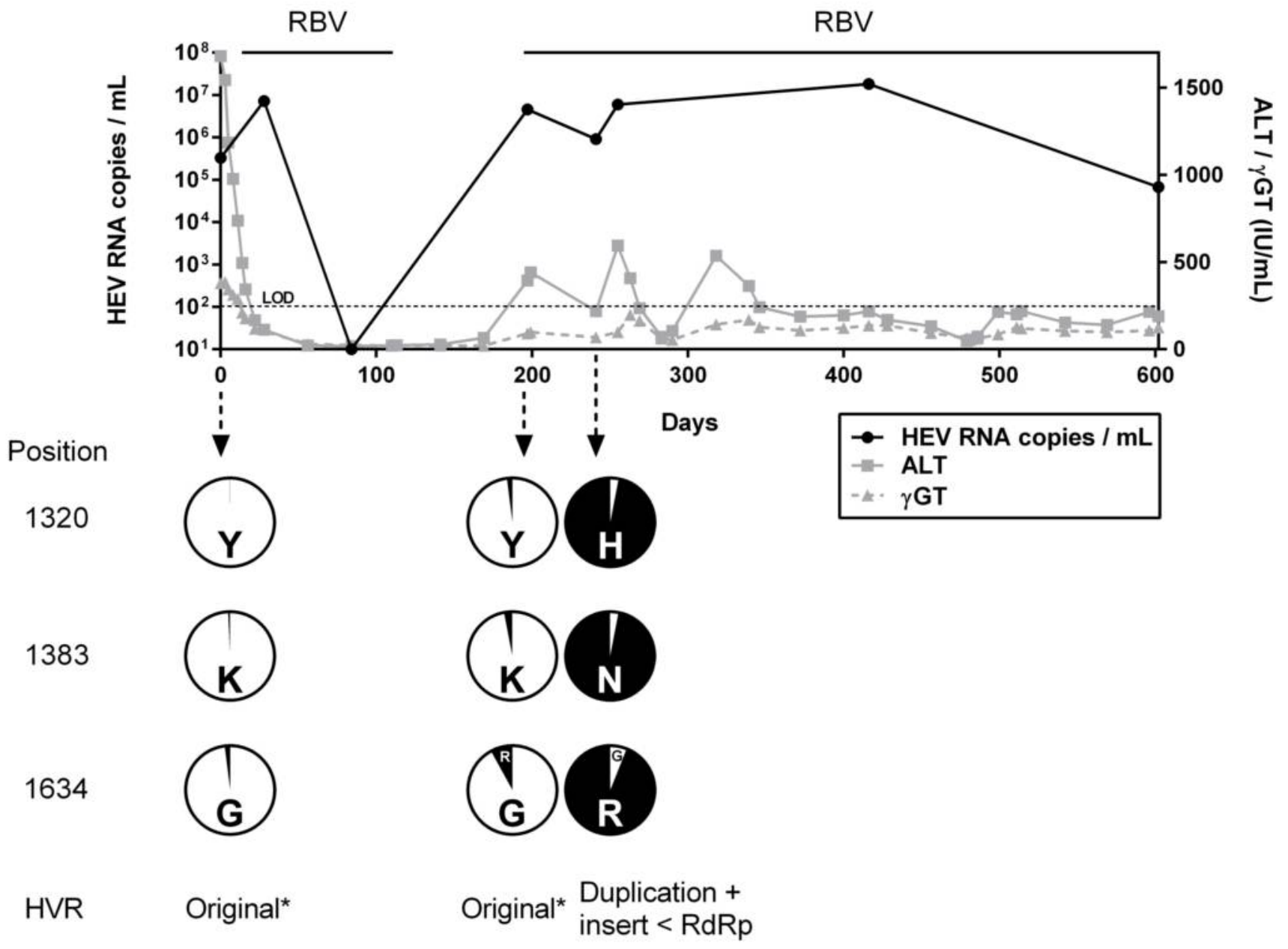

\section{Hypervariable region} $\begin{array}{lll}\text { preRBVres } & 593 & \text { TFDDSRQAMGAGPHNLTYELVPAGLQVKISSNGLDCTAIFPPGAAPSAAPSEVAAFCSAL. } \\ \text { relapse } & 593 & \text { TFDDSRQAMGAGPHNLTYELVPAGLQVKISSNGLDCTAIFPPGAAPSAAPSEVATFCSAL }\end{array}$ postRBVres 593 TFDDSRQAMGAGPHNLTYELVPAGLQVKISSNGLDCTAIFPPGAAPSAAPSEVAAFCSAL

PreRBVres 653 YRYNKFTQRHSLTGGLWLYPEGLLGLFPPFSPGHLWESANPFCGESTLYTRTWSTSGFS: relapse 653 YRYNKFTQRHSLTGGLWLYPEGLLGLEPPF SPGHLWESANPFCGESTLYTRTWSTSGFSS postRBVres 653

preRBVres 713 relapse 713 postRBVres 713

preRBVres 773 relapse 773 postRBVres 773

preRBVres 793 relapse 793 postRBVres 833
YRYNKFTQRHSLTGGLWLYPEGLLGLFPPF SPGHLWESANPFCGESTLYTRTWSTSGESS

DESPPEAAHAAPVPDVGLPSGAPSSASDVWVFPPPSEGSAIVPPPETPVSKPANPPCSIT DESPPEAAHAAPVPDVGLPSGAPSSASDVWVFPPSEGSAIVPPPETPVSKPANPPCSII DESPPEAAHAVVVPDVGLPSGAPSSASDVWVFPPPSEGSAIVPPPETPVSKPANPPCSII

PRPPVRKPPTPPPARTRRLL-

PRPPVRKPPTPPPARTRRLL-PRPPVRKPPTPPPARTRRL 1 SLKGFWKKISGFSSDFSPPEAAHAVPVPDVLLPGAPSSA $\rightarrow$ RdRp

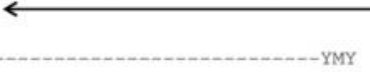

SDVWVEPPPSEGSAIVPPPETPVSKPANPPCSITPRPPVRKPPTPPPARTRRLLYMY

\section{C}

\section{RNA-dependent RNA polymerase}

PreRBVres 1207 GGEVGHHRPSTIPRGNPDQNLDTLRAFPPSCOISAYHOLAEELGHRPAPVAAVLPPCPEL relapse 1207 GGEVGHHRPSTIPRGNPDONLDTLRAFPPSCOISAYHOLAEELGHRPAPVAAVLPPCPEL postRBVres 1207 GGEVGHHRPSTIPRGNPDQNLDTLRAFPPSCOISAYHQLAEELGHRPAPVAAVLPPCPEL

preRBVres 1267 EQGLLYMPQELTVSDSVLIFELTDIVHCRMAAPSORKAVLSTLVGRYGRTKLYEAAHSD relapse 1267 EOGLLYMPQELTVSDSVLIFELTDIVHCRMAAPSORKAVLSTLVGRYGRTKLYEAAHSD postRBVres 1267 EQGLLYMPQELTVSDSVLIFELTDIVHCRMAAPSQRKAVLSTLVGRYGRRTKLHEAAHSD

PreRBVres 1327 VRESLGRE IPTIGPVOATTCELYELVEAMVEKGQDGSAVLELDLCSRDVSRITFE CKDCD relapse 1327 VRESLGREIPTIGPVQATTCELYELVEAMVEKGQDGSAVLELDLCSRDVSRITFF KDCL postRBVres 1327 VRESLGREIPTIGPVQATTCELYELVEAMVEKGODGSAVLELDLCSRDVSRITFFQNDCA F1 motif

preRBVres 1387 KFTIGETIAHGKVGQGISAWSKTFCALFGPWFRAIEKETLALLPPNIFYGDAYEETVFSA relapse 1387 KFTTGETIAHGKVGQGISAWSKTFCALFGPWFRAIEKEILALLPPNIFYGDAYEETVFSA postRBVres 1387 KFTTGETIAHGKVGQGISAWSKTFCALFGPWFRAIEKETLALLPPNIFYGDAYEETVFSA

preRBVres 1447 AISGAGSSMVEENDFSEFDSTONNF SLGLECVIMEECGMPQWLIRLYHLVRSAWTLQAPK relapse 1447 AISGAGSSMVEENDF SEFDSTQNNF SLGLECVIMEECGMPQWLIRLYHLVRSAWTLQAPK postRBVres 1447 AISGAGSSMVFENDFSEFDSTONNFSLGLECVIMEECGMPOWLIRLYHLVRSANTLQAPK

preRBVres 1507 LLKGWK ASGEPGTLLWNTVWNMAIIAHCYEFRDLRVAAFKGDDSVVLCSDYROSRNA relapse 1507 DLKGFWKR ISGEPGTLLWNTVWNMAI IAHCYEFRDLRVAAFKGDDSVVLCSDYRQSRNA postRBVres 1507 LLKGFWK ISGEPGTLLWNTVWMMAI IAHCYEFRDLRVAAFKGDDSVVLCSDYRQSRNA HVR insert origin

preRBVres 1567 ATL.IAGCGLKLKVDYRPIGLYAGVVVAPGLGALPDVVRFAGRLSEKNWGPGPERAEQLRL relapse 1567 ATLTAGCGLKLKVDYRPTGLYAGVVYAPGLGALPDVVRFAGRLSEKNWGPGPERAEOLLL postRBVres 1567 ATLIAGCGL.KLKVDYRPIGLYAGVVVAPGLGALPDVVRFAGRLSEKWWGPGPERAEOLRI

preRBVres 1627 AVCDFLRGLTNVAQVCVDVVSRVYGVSPGLVHNLIGMLQTIADGKAHFTETVKPVLDLTI relapse 1627 AVCDFLRGLTNVAQVCVDVVSRVYGVSPGLVHNLIGMLOTIADGKAHFTETVKPVLDLTM postRBVres 1627 AVCDFLRRLTNVAQVCVDVVSRVYGVSPGLVHNLIGMLOTIADGKAHFTETVKPVLDLTN

PreRBVres 1687 SIIQRLE

relapse 1687 SIIORLE

postRBVres 1687 SIIORLB 


\section{Figure 2}

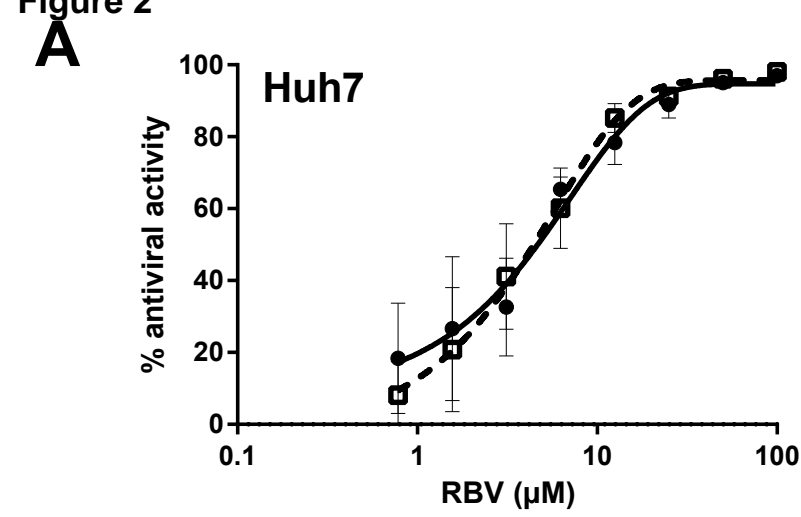

$\rightarrow p 6 / l u c$

- $\mathrm{p}$ 6/RdRp $p_{\text {preRBVres }} /$ luc

D

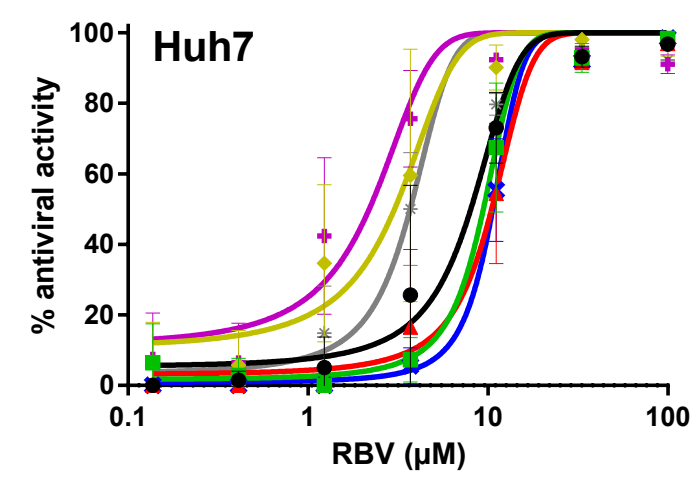

G

$$
\begin{array}{ll}
\rightarrow \text { YKG } & \text { * HKR } \\
=\text { HKG } & \text { - YNR } \\
\text { - YKR } & \text { * HNR }
\end{array}
$$

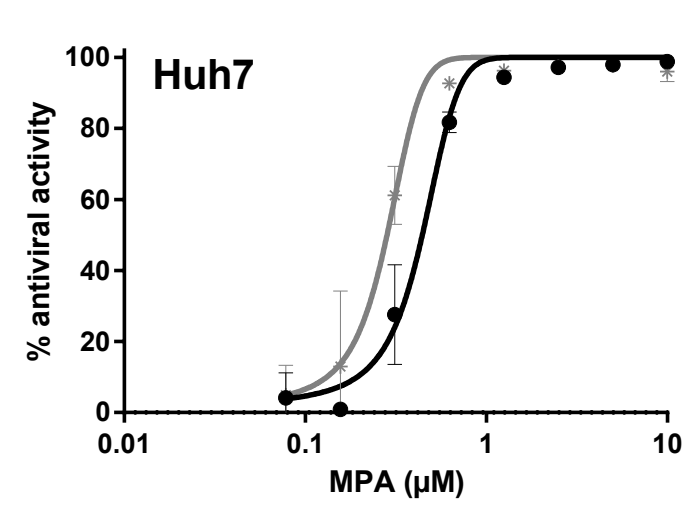

$\rightarrow$ YKG
B

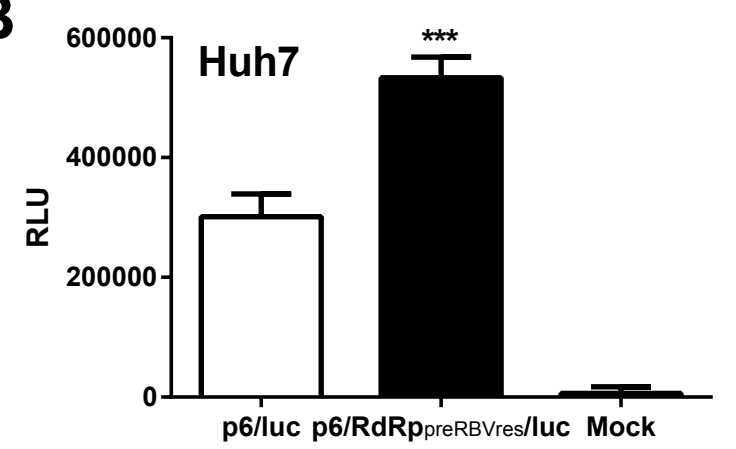

E

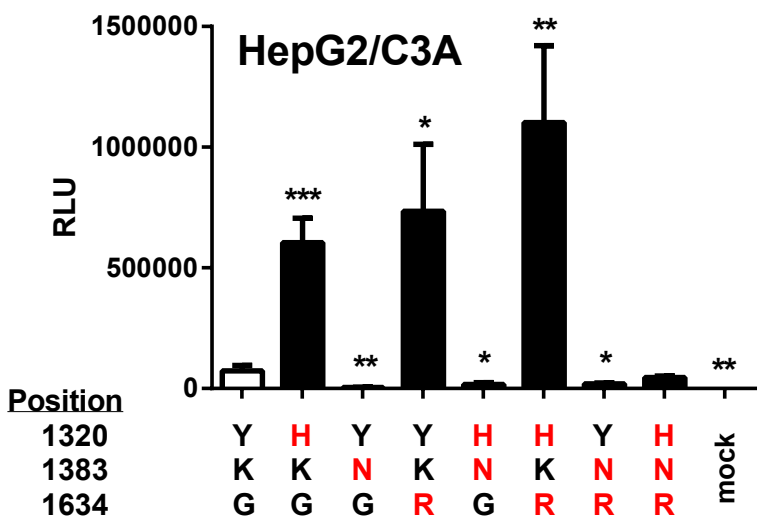

p6/RdRp preRBVres $/$ luc mutants

H

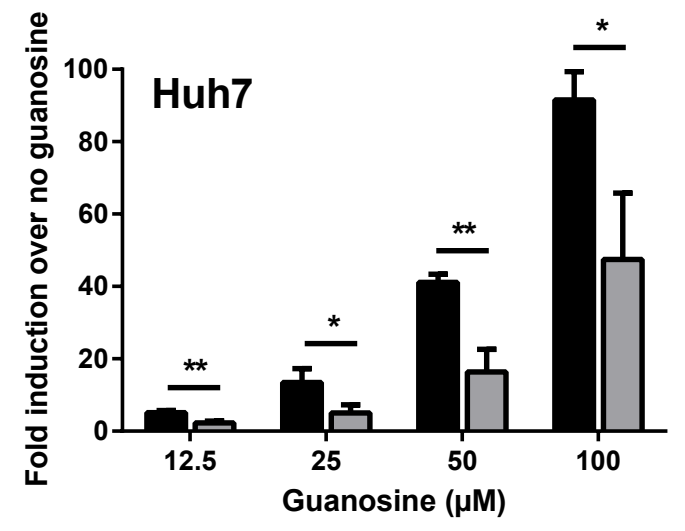

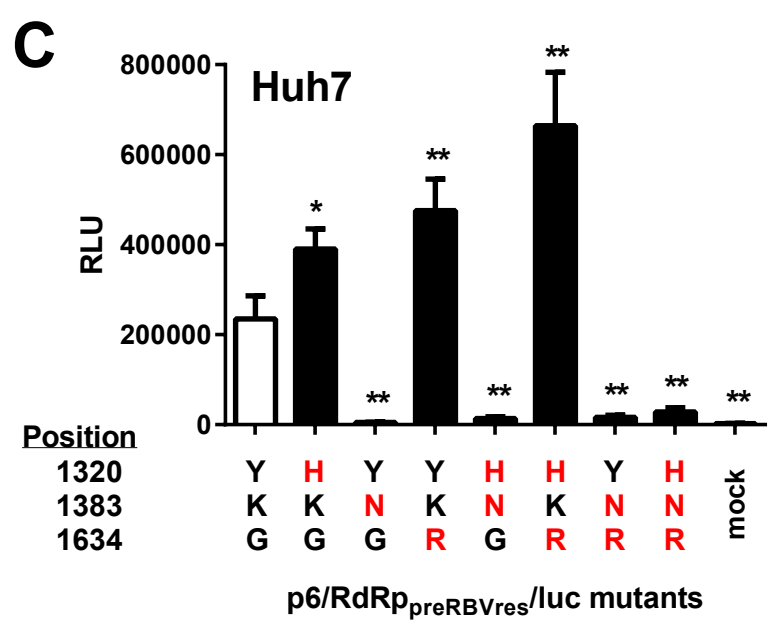

F

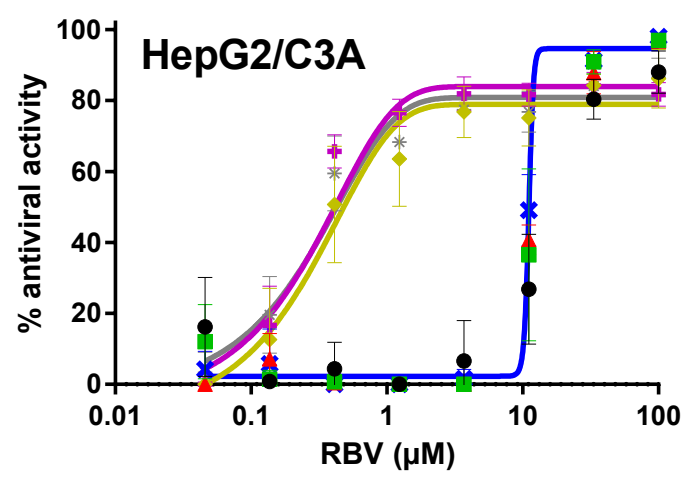

$$
\begin{array}{ll}
\rightarrow \text { YKG } & \text { * HKR } \\
\approx \text { HKG } & + \text { YNR } \\
=\text { YKR } & \text { HNR } \\
\approx \text { HNG } &
\end{array}
$$

YKG $\square$ HNR 


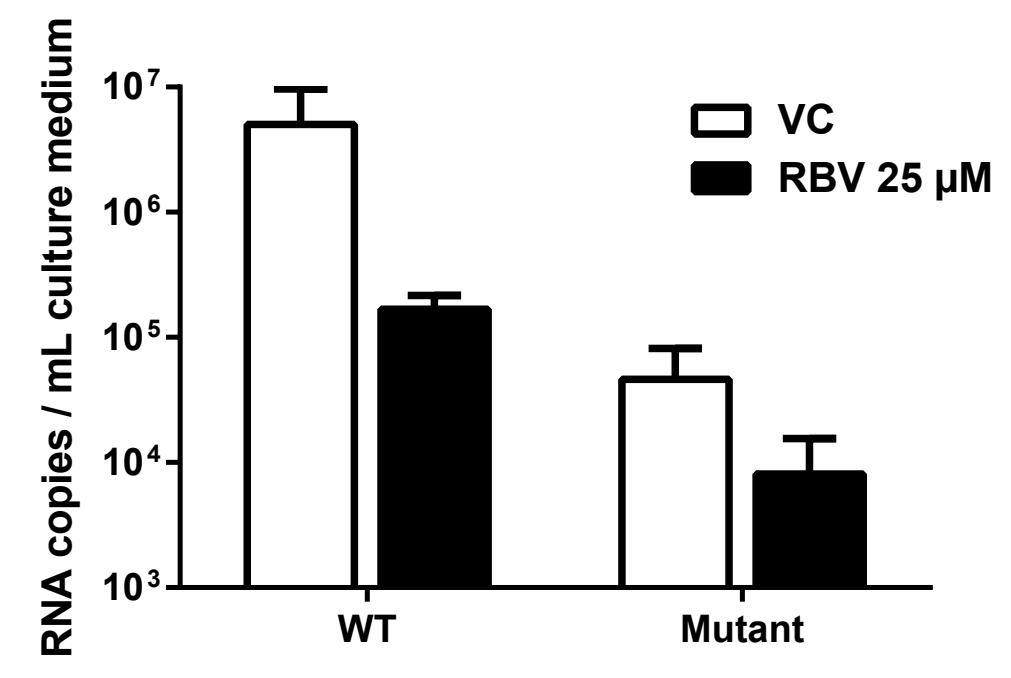

HepG2/C3A + FBS

Huh7 + HS
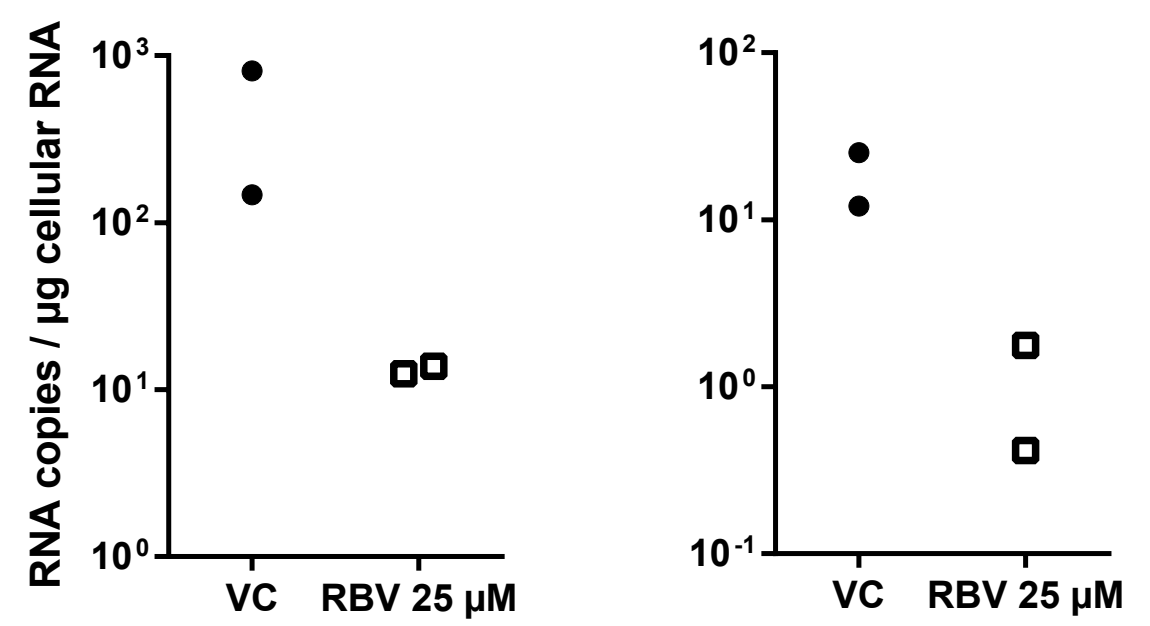


\section{ORF1}

p6/luc

\begin{tabular}{|l|l|l|l|}
\hline & HVR & & RdRp \\
\hline
\end{tabular}

p6/HVR postRBVres /luc

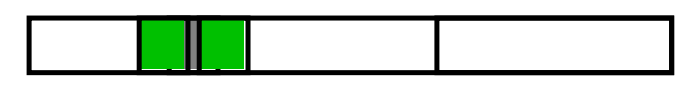

p6/RdRp postRBVres lluc

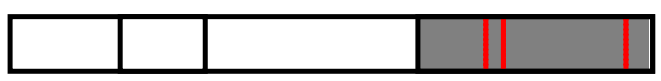

p6/RdRp+HVR postRBVres $_{\text {/luc }}$
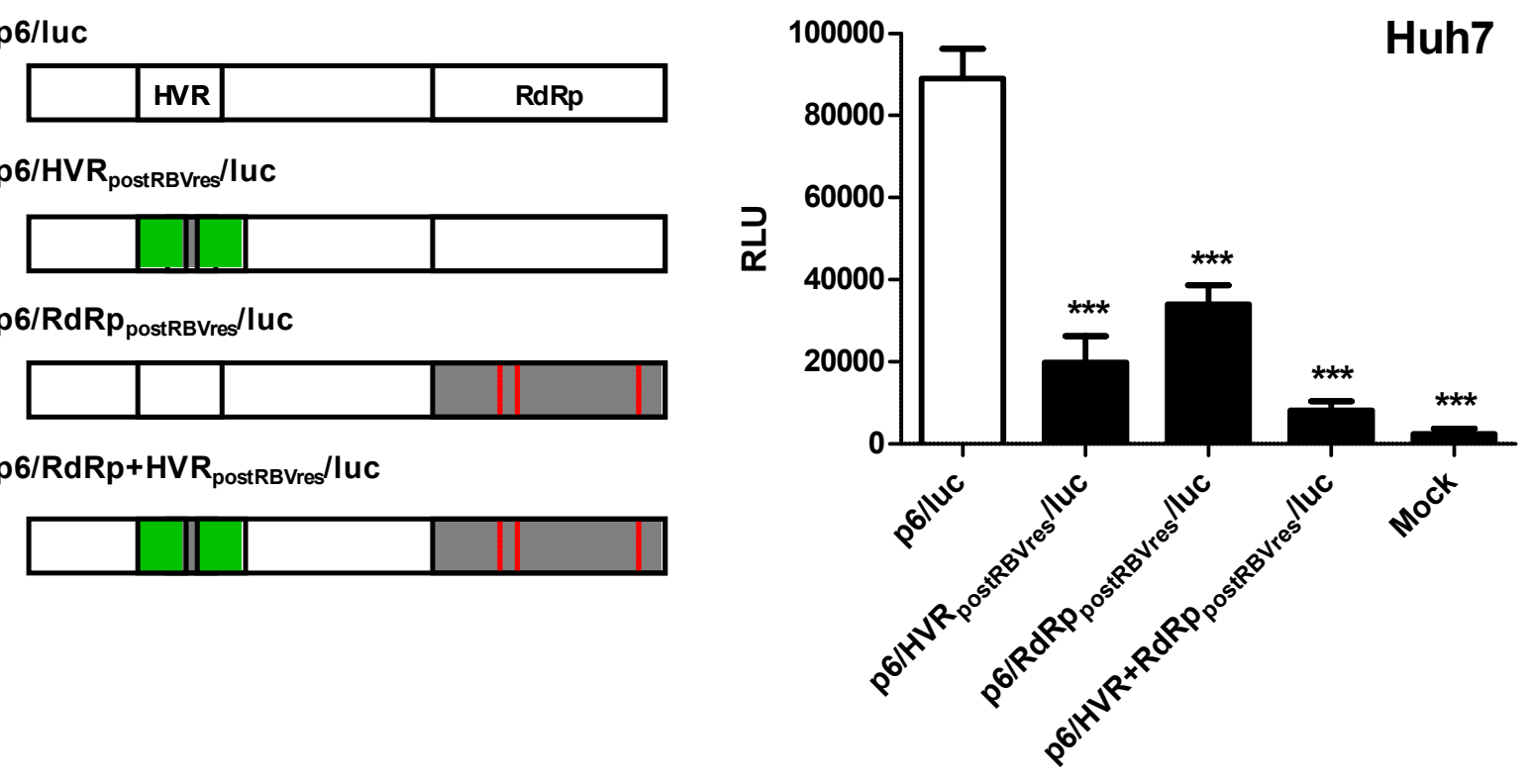

D

HVR

Pre

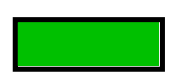

Pre A723V

Post

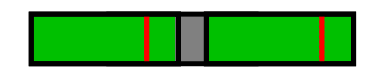

Post - insert

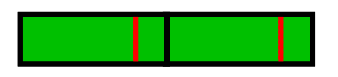

Pre + insert

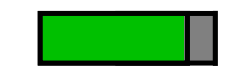

E

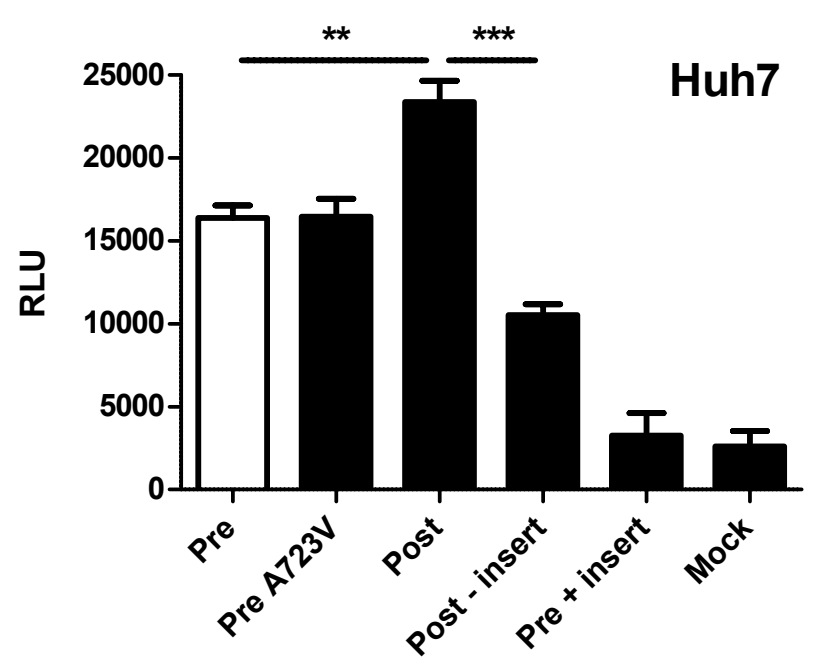

p6/HVR RBVres $_{\text {luc }}$
C

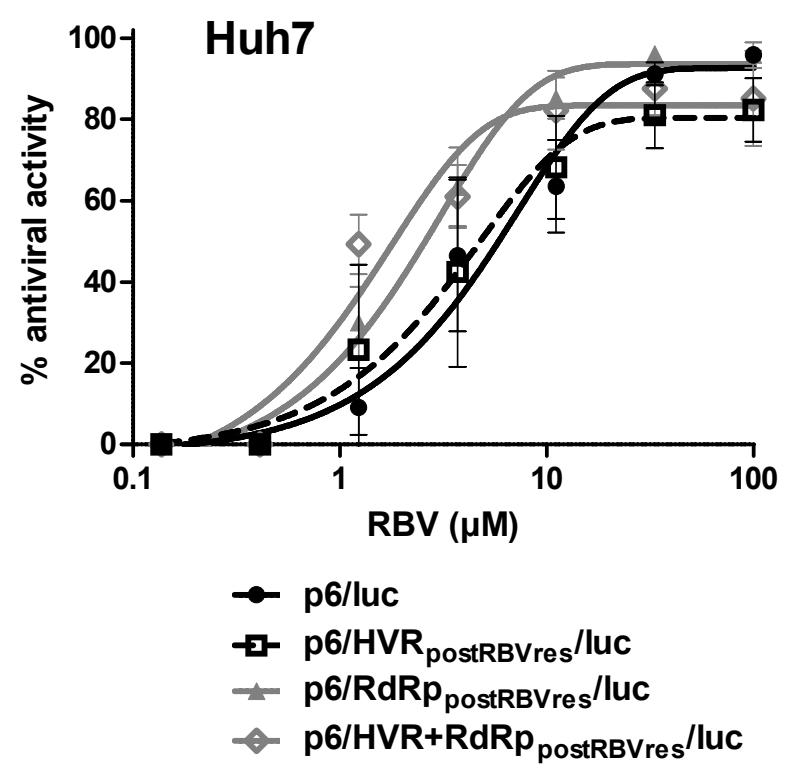

F

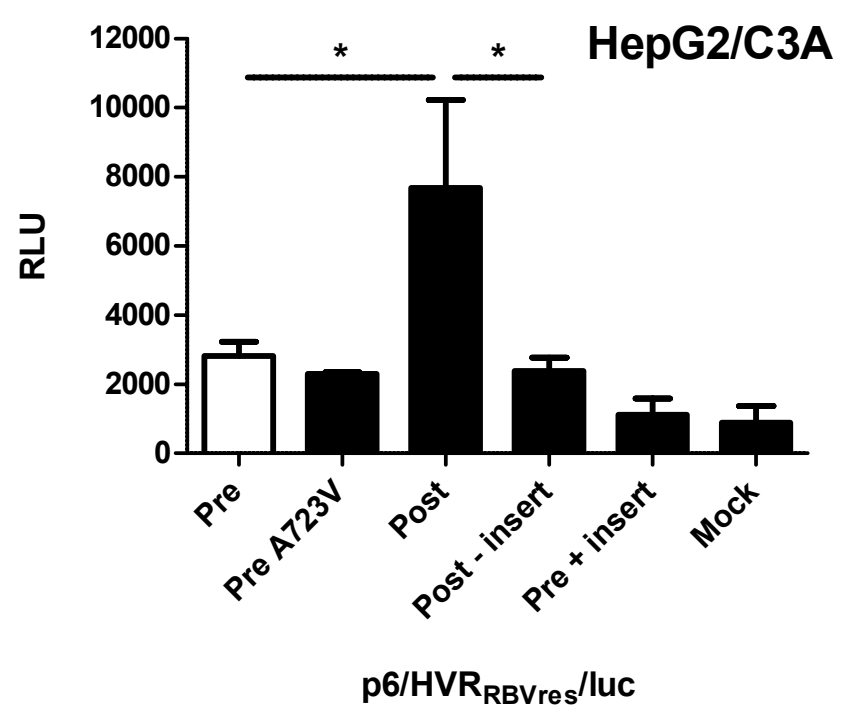




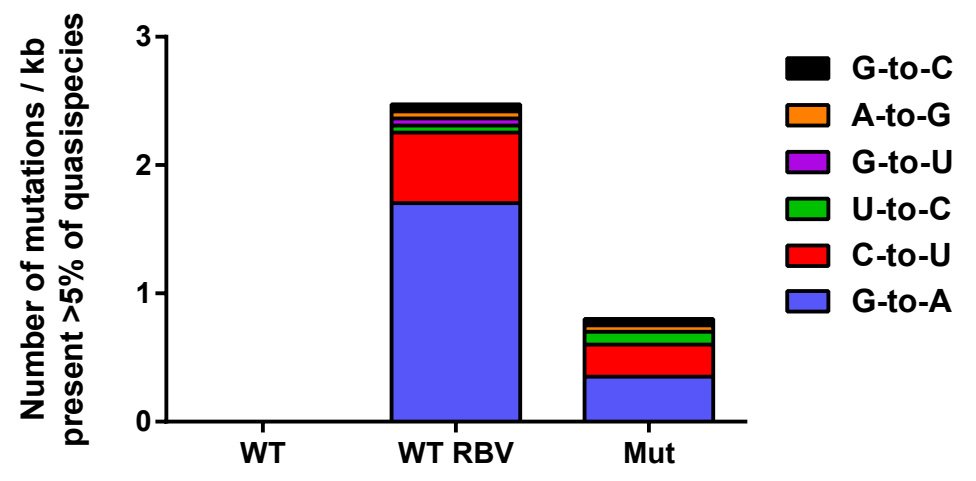

B

\section{HEV WT VC $(n=3)$}

HEV WT RBV
Exp. 1
HEV WT RBV
Exp. 2

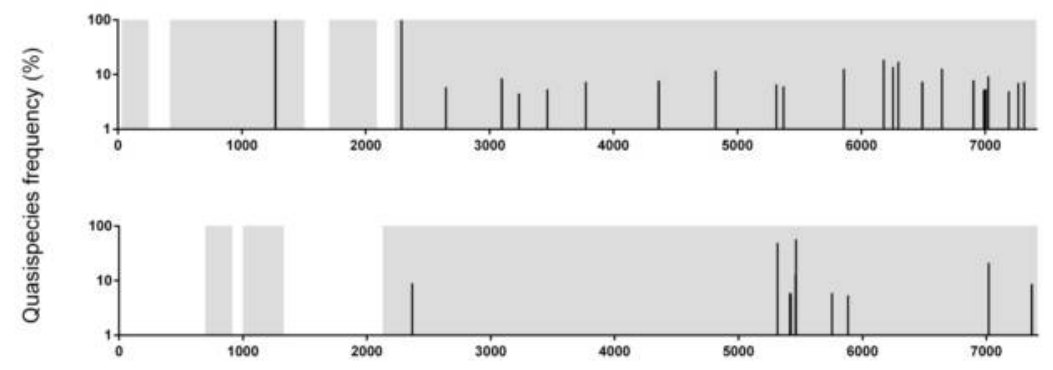

HEV WT RBV Exp. 3

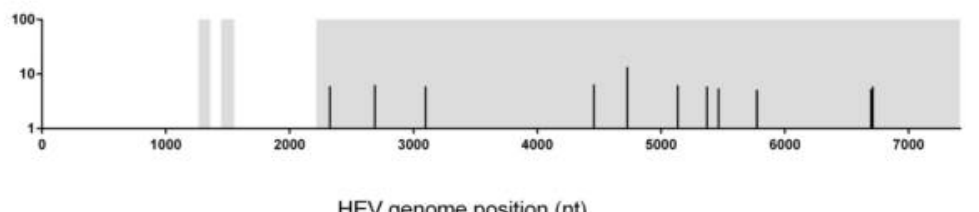

C

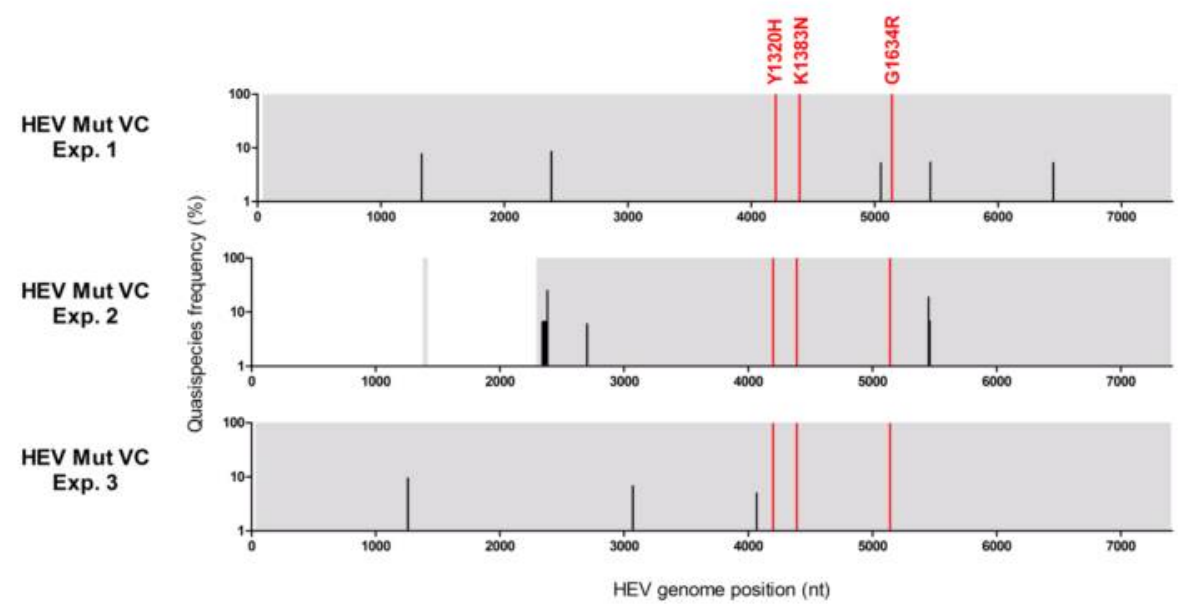


A

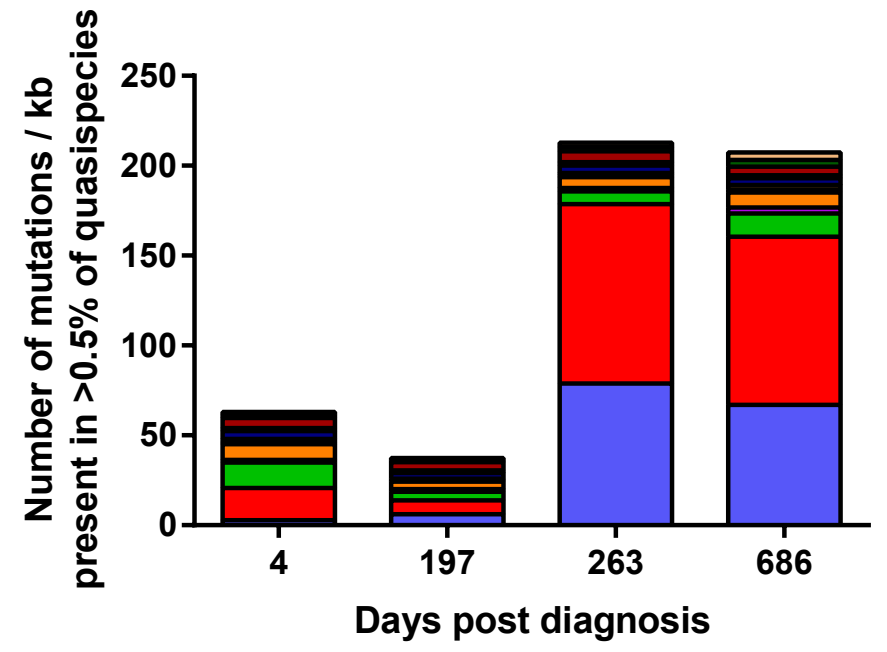

B

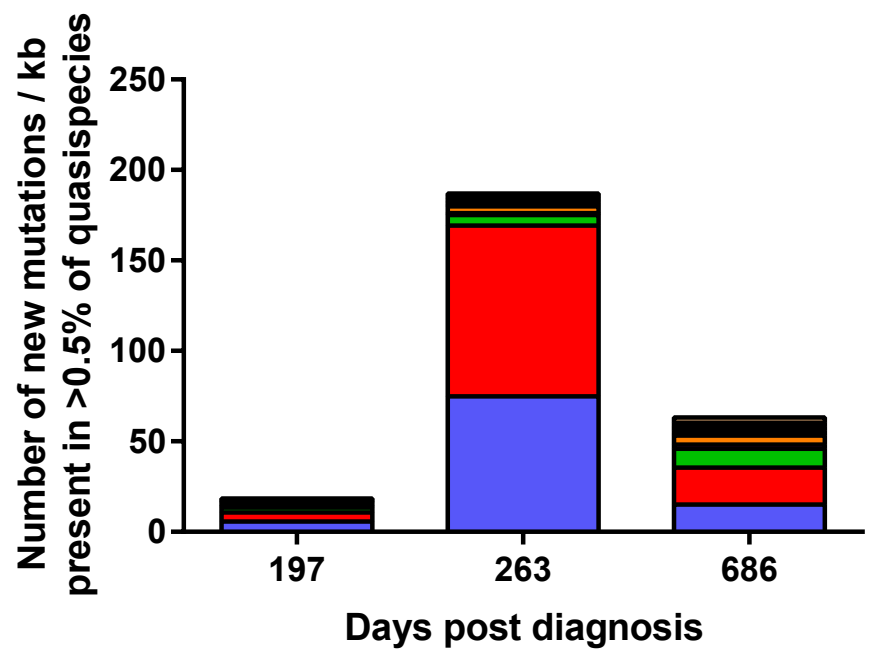

$\square$ C-to-A

$\square$ A-to-U

$\square$ U-to-G

$\square$ C-to-G

a-to-C

$\square$ U-to-A

- G-to-C

$\square$ A-to-G

$\square$ G-to-U

$\square$ U-to-C

$\square$ C-to-U

$\square$ G-to-A 
Figure 7

ORF1

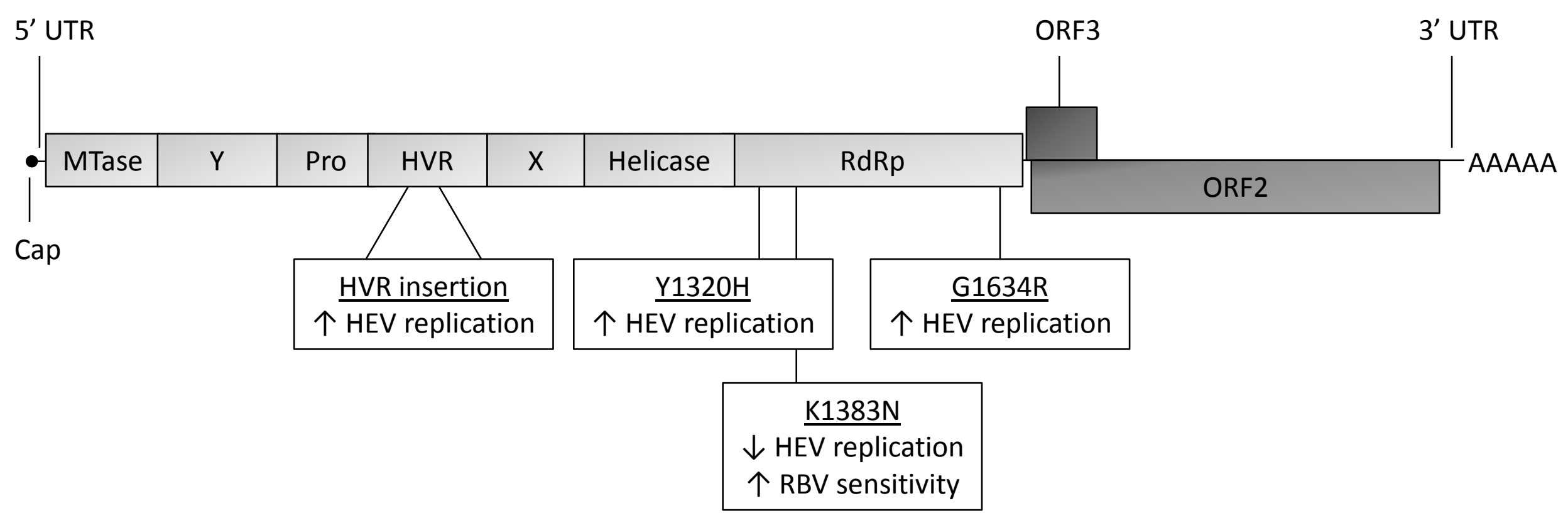

\section{Hypothesis:}

- $\mathrm{Y} 1320 \mathrm{H}, \mathrm{G} 1634 \mathrm{R}$ and the HVR insertion compensate for the $\mathrm{K} 1383 \mathrm{~N}$-associated replication defect

- K1383N may play a crucial role in RBV resistance by altering RdRp fidelity 
